\title{
A influência protestante na obra de Othoniel Motta e sua importância para a educação brasileira
}

\author{
Wendell Lessa Vilela Xavier ${ }^{1}$
}

\begin{abstract}
Resumo
Este texto é resultado de pesquisa documental referente à vida e obra do gramático protestante Othoniel de Campos Motta e sua influência na educação brasileira. Baseandose nos textos gramaticais produzidos pelo autor, verifica-se a numerosa produção bibliográfica e sua repercussão histórica no cenário educacional brasileiro. As fontes utilizadas para esta pesquisa constituem-se da literatura e material didático produzidos por Othoniel Motta bem como de textos analíticos de teólogos e historiadores que demonstram a maciça influência protestante e especialmente puritana na educação da Inglaterra puritana a partir do século 17, dos Estados Unidos e do Brasil. Para fundamentar teoricamente a análise, utiliza-se da historiografia de Christopher Hill (2012) que considera a relevância dos puritanos para a amplificação da consciência educacional inglesa no século 17. Para demonstração da influência dos herdeiros dos puritanos ingleses no sistema educacional norte-americano, utilizam-se James Packer (1996) e Leland Ryken (1992). Aliado a esses pensadores, soma-se a ideia de Abraham Kuyper (2002), fundador e reitor da Universidade Livre de Amsterdã, para quem o calvinismo não é apenas contemplação, mas restaurou a ciência ao seu domínio e deu a ela a liberdade perdida pelas visões reducionistas de sua época. A relevância desta abordagem está na problematização de uma visão de mundo e práticas educativas dela decorrentes, possibilitando reflexões sobre os seus efeitos na esfera pública.
\end{abstract}

Palavras-chave: Othoniel Motta; Puritanismo; Protestantismo; Educação Brasileira

\section{The Protestant influence on the work of Othoniel Motta and its importance for Brazilian education}

\begin{abstract}
:
This text is the result of documentary research regarding the life and work of the Protestant grammarian Othoniel de Campos Motta and his influence on Brazilian education. Based on the texts grammatical produced by the author, the numerous bibliographic production and its historical repercussion in the Brazilian educational scenario. The sources used for this research they consist of literature and teaching material produced by Othoniel Motta as well as of analytical texts by theologians and historians who demonstrate the massive Protestant influence and especially Puritan in the education of Puritan England from the 17th century onwards, from the States United States and Brazil. To theoretically support the analysis, the historiography of Christopher Hill (2012) who considers the relevance of Puritans to the amplification of English educational \footnotetext{
wendell.xavier@ifnmg.edu.br. ORCID: https://orcid.org/0000-0002-7955-2785.
}

${ }^{1}$ Doutor em Letras. Professor Efetivo do Instituto Federal do Norte de Minas Gerais - IFNMG. E-mail:
\end{abstract}


conscience in the 17th century. To demonstrate the influence of heirs of English Puritans in the North American educational system, James Packer is used (1996) and Leland Ryken (1992). Allied to these thinkers, the idea of Abraham is added Kuyper (2002), founder and rector of the Free University of Amsterdam, for whom Calvinism it is not just contemplation, but it has restored science to its domain and given it freedom lost by the reductionist visions of its time. The relevance of this approach is in the problematization of a worldview and educational practices arising from it, enabling reflections on its effects in the public sphere.

Keywords: Othoniel Motta; Puritanism; Protestantism; Brazilian Education

\section{La influencia protestante en la obra de Othoniel Motta y su importancia para la educación brasileña}

\section{Resumen:}

Este texto es el resultado de una investigación documental sobre la vida y obra del gramático protestante Othoniel de Campos Motta y su influencia en la educación brasileña. Basado en los textos gramatical producido por el autor, la numerosa producción bibliográfica y su repercusión histórica en el escenario educativo brasileño. Las fuentes utilizadas para esta investigación Consisten en literatura y material didáctico producido por Othoniel Motta, así como de textos analíticos de teólogos e historiadores que demuestran la masiva influencia protestante y especialmente puritana en la educación de la Inglaterra puritana desde el siglo XVII en adelante, desde los Estados Estados Unidos y Brasil. Para sustentar teóricamente el análisis, la historiografía de Christopher Hill (2012) quien considera la relevancia de los puritanos para la amplificación de La conciencia educativa inglesa en el siglo XVII. Demostrar la influencia de los herederos de los puritanos ingleses en el sistema educativo norteamericano, James Packer se utiliza (1996) y Leland Ryken (1992). Aliado a estos pensadores, se suma la idea de Abraham Kuyper (2002), fundador y rector de la Universidad Libre de Amsterdam, para quien el calvinismo no es solo contemplación, sino que ha devuelto la ciencia a su dominio y le ha dado libertad perdido por las visiones reduccionistas de su tiempo. La relevancia de este enfoque radica en la problematización de una cosmovisión y prácticas educativas que surgen de ella, possibilitando reflexiones sobre sus efectos en la esfera pública.

Palabras llave: Othoniel Motta; Puritanismo; Protestantismo; Educación Brasileña

"Senhor, por escolas em todo lugar entre nós! [...] Oh, que nossas escolas possam florescer! Que cada membro desta assembleia possa ir para casa e consiga uma boa escola para ser encorajado na cidade onde mora!", orou o puritano John Eliot em um Sínodo realizado entre as igrejas de Boston durante o século 17. Em 1647, uma lei em Massachusetts ordenou a criação de escolas. Em 1650, Connecticut fez o mesmo. Em 1655, o Código de New Haven ordenou a todos os pais e mestres que providenciassem meios para ensinar os filhos e aprendizes (RYKEN, 1992:167-168). O homeschooling sempre foi algo comum na educação. Entre os cristãos protestantes e puritanos não era 
diferente. E o desejo dos pais puritanos de espalhar o que consideravam o verdadeiro conhecimento para toda a sociedade.

Os protestantes sempre tiveram participação efetiva na educação e na urbanidade, não somente no Brasil, mas no mundo, especialmente na Europa e nos Estados Unidos a partir do século 17. Christopher Hill (2012:27), por exemplo, ao mencionar a relação entre "presbiterianos" e "independentes" e o avanço da indústria em Londres e nas cidades vizinhas, afirmou que "os mercadores londrinos fundaram escolas primárias e secundárias, concederam bolsas de estudos ou favoreceram pregações nos condados onde haviam nascido e, assim, ajudaram a promover o nível intelectual ou cultural das áreas afastadas da City".

Hill chega a mencionar um importante pastor puritano, Richard Baxter, ao elogiar o contato dos londrinos com os tecelões de Kidderminster, destacando que "seu constante contato e comunicação com Londres realmente promovem a urbanidade e a religiosidade entre os comerciantes" (2012:27).

Richard Baxter, por exemplo, foi um "mestre-escola por instinto" (PACKER, 1991:328). Foi um parlamentar brilhante e um evangelista pastoral que entendia que seu ministério era o ensino. De acordo com James Packer, "Baxter usualmente chamava a si mesmo de professor de sua gente, e, de acordo com sua maneira de pensar, ensinar era a principal tarefa de um pastor" (1991:328).

O ensino desenvolvido por Baxter não se restringia apenas aos frequentadores de sua paróquia. Em sua cidade, Kidderminster, havia cerca de oitocentas famílias e dois mil adultos. Baxter visitava todas essas pessoas, ensinando a elas a Bíblia e os princípios cristãos. Baxter atendia às famílias que vinham à sua paróquia, bem como ia às casas delas. Para ele, o que importava era alcançar cada coração com o ensino.

De acordo com Hill, eram os mercadores londrinos e os puritanos, em sua maioria, os que praticavam a caridade naquela época, especialmente encorajando os mercadores ao comércio justo e crescente, a remodelar a sociedade da melhor forma, estabelecendo escolas, asilos para pobres, crédito para aprendizes, dentre outros benefícios (HILL, 2012:31).

Havia acúmulo de riqueza na Inglaterra do século 17, e a concentração dessas riquezas desagradava boa parte dos puritanos, que queriam que "a receita dos bispos, reitores e colegiados da Igreja financiasse um ministério de pregação em cada paróquia 
e, com isso, abolisse o pluralismo, bem como estabelecesse escolas e prestasse assistência aos necessitados" (HILL, 2012:96).

A principal intenção social dos puritanos era estabelecer escolas com bolsas de estudos, garantindo a assistência aos mais necessitados, a fim de que eles pudessem ter acesso ao conhecimento e usar esse conhecimento para o benefício da sociedade. $\mathrm{O}$ conhecimento traria acesso aos bens que, por sua vez, produziria a riqueza necessária para o desenvolvimento e para o cuidado com os mais carentes. Ryken destaca que o número de escolas primárias dobrou enquanto os puritanos estavam em ascensão (1992:168).

Hill destaca que os projetos puritanos de aplicar os espólios da Igreja no avanço do conhecimento nunca de realizaram plenamente. Mas, apesar disso, as universidades foram liberadas de tributação e os diretores de Oxford e Cambridge receberam aumentos de salário. Além disso, novas escolas foram fundadas. Pelo menos 55 escolas foram estabelecidas entre 1651 e 1653 (2012:194).

Como destacou Leland Ryken, "na América, nenhum dos outros colonizadores de fala inglesa estabeleceu tão cedo a educação universitária após sua chegada quanto o fizeram os Puritanos" (RYKEN, 1992:167). Ryken enfatiza que após apenas seis anos da chegada dos puritanos em Massachusetts, o Tribunal Geral votou uma verba de quatrocentas libras para aplicar em uma escola ou faculdade. Em razão desse esforço, a Universidade de Havard foi mantida durante um bom período por fazendeiros puritanos que contribuíam com a venda do trigo para sustentar professores e alunos (RYKEN, 1992:167).

\section{$O$ valor da ciência para o protestante}

De acordo com Alvin Plantinga (2018), o surgimento da ciência moderna foi "o fenômeno intelectual mais admirável e marcante dos últimos quinhentos anos”, elevando o valor da ciência a um estado de empreendimento cooperativo. Todavia, os cristãos protestantes reformados entendem que não se deve reduzir a experiência humana ao seu escopo. Aliás, nem a própria ciência se atreveu a assumir esse ônus. Embora a ciência tente explicar fenômenos, o verdadeiro cientista compreende que não deve pretender absolutos de todos os tópicos da realidade humana.

A ciência é valiosa, é admirável, marcante, mas não é toda a verdade. Ela é parte da verdade, como uma peça de um quebra-cabeça é parte dele, mas não é ele todo. Ela é 
apenas um meio instrumental que devemos usar para compreender melhor a verdade que aparece aos nossos olhos. Mas a ciência não domina a verdade. A ciência também se corrompe, se perde, se vende e se falseia, porque essa degeneração moral é própria dos seres humanos falíveis. E não é difícil falsear a ciência ou permitir que ela nos manipule, assim como não é difícil nem raro o falseamento da religião e da política. Qualquer área da realidade humana pode se tornar escrava de certas ideologias perniciosas que pretendem mais obscurecer do que revelar a verdade. É assim na religião, na política e, também, na ciência.

Os cristãos protestantes entendem é que há muito mais para se descobrir da realidade humana do que a ciência pode nos oferecer. Existe gigantesca inteligibilidade no mundo que reflete uma harmoniosa precisão com as nossas mentes que estão para além da ciência. Há uma realidade escondida para onde as mentes inquiridoras se dirigem. Existem pistas lançadas ao longo do nosso caminho que insistem em nos mostrar algo de nossa existência que por vezes tentamos negar. E é por essa busca inquiridora sensível por meio de nossas antenas espirituais e intelectuais que vamos, passo a passo, em busca da descoberta.

Nesse sentido, Abraham Kuyper (2002:133) defendeu que a ciência pode exercer sua liberdade dentro da compreensão de que ela é limitada pelo próprio ser de Deus, criador e sustentador de todas as coisas. Ao compreender seu domínio, a ciência caminha livremente a fim de colaborar com a revelação de Deus para a humanidade. O cientista, portanto, é um divulgador das obras da criação, um perscrutador da natureza, a fim de revelar aos demais as belezas criativas de Deus. A ciência não cria, ela descobre. Ela procura entender aquilo que por Deus deseja ser revelado.

Nas palavras do teólogo Herman Bavinck:

Quando se trata do conhecimento das coisas criadas, a situação é um pouco diferente. Mesmo que, no empreendimento desse conhecimento, sejamos absolutamente dependentes de Deus, ainda assim, na Criação, ele encarregou o homem da tarefa de subjugar e dominar toda a terra, o equipou e deu-lhe o interesse de fazer isso. O homem está acima da natureza, e pode tomar a medida do fenômeno natural, estudá-lo e, em certa medida, artisticamente criar coisas. Ele pode, de certa forma, forçar a natureza a se revelar e descobrir seus segredos. Porém, essa habilidade também é limitada de todas as formas. Conforme a ciência penetra cada vez mais profundamente no fenômeno e se aproxima da essência das coisas, ela vê os mistérios aumentando e ela mesma encurralada pelo incompreensível. Não são poucos os que estão tão 
profundamente convictos das limitações do conhecimento humano, que dizem: "não sabemos", e às vezes acrescentam: "e nunca saberemos".

\section{A educação no Brasil}

Em São Paulo dos anos 1889 a 1920, os avanços sócio-econômicos produziram uma aceleração do desenvolvimento educacional no estado. A rápida expansão da indústria cafeeira e o estabelecimento do estado de São Paulo como o eixo da vida econômica nacional, gerando o crescimento populacional, a ativação da urbanização, dentre outros fatores correlatos criaram o contexto necessário para os processos de mudança em relação à educação.

Antunha (1976) relaciona alguns aspectos que despertaram o interesse das autoridades educacionais do estado, a saber: a. a necessidade de expansão da rede escolar, a fim de acompanhar o crescimento da população; b. a escolarização das zonas novas, de intensa mobilidade populacional, com as consequentes dificuldades de localização dos núcleos da população infantil, de acomodação dos professores etc; c. a integração dos imigrantes e de seus filhos na vida nacional; d. a melhoria do nível da população nacional das classes mais pobres.

A fase crítica ou de transição foi a de 1910 a 1920. Foi neste período que surgiram críticas apontando a necessidade urgente de uma reforma na educação do estado, a fim de ajustá-lo aos requerimentos sociais. Antunha (1976) registrou que não havia em São Paulo no período que vai praticamente até 1920, preocupações teóricas que ultrapassem o nível da metodologia e da técnica de ensino, ou críticas e sugestões sobre a problemática mais evidente.

A preocupação de integrar o caboclo e o estrangeiro, chegados a São Paulo, a uma cultura brasileira foi um fator motivacional para as reformas na educação do estado. A fim de atingir a todos os recantos do estado e a todas as crianças, a criação de escolas era um ideal de nacionalismo. Nestas escolas, poderiam ser definidas as principais áreas de integração nacional: a língua, a história, nos seus valores tipicamente cívicos e brasileiros.

Em relação ao ensino ginasial, até 1930 os ginásios eram, em sua maioria, mantidos por particulares, exceto os três ginásios estaduais: o da Capital, o de Campinas e o de Ribeirão Preto. Os ginásios seguiam um modelo aristocrático, predominantemente frequentado por homens, que ambicionavam as escolas superiores. Uma explicação possível para esta preferência masculina está no fato de que as mulheres davam 
preferência ao curso normal. Segundo Antunha (1976:88), em 1909, por exemplo, o Instituto Ciências e Letras apresentava matrícula de 263 alunos, sendo apenas 30 mulheres; no Ginásio Macedo Soares, dos 294 matriculados apenas 52 eram mulheres.

As dificuldades enfrentadas por estas instituições para atrair novos alunos era grande. Os dados relativos à matrícula no ano de 1909 indicavam 471 alunos nos três estabelecimentos do Estado e 2.326 em 14 estabelecimentos particulares. O número de diplomados em 1909 era o seguinte: 21 alunos na Capital e em Campinas, e 93 alunos nos estabelecimentos privados. A situação, portanto, no início de funcionamento destas instituições de ensino era muito grave, e a exigência de uma política educacional ou de uma reforma localizada aumentava.

Além da necessidade de reforma estrutural no que se referia à administração política e econômica das instituições, havia também a questão dos currículos. A escolha das disciplinas que compunham os cursos passava por uma decisão política. Por esta razão, o corpo docente dos ginásios era, normalmente, o que havia de melhor no país: Eduardo Carlos Pereira, Oscar Pereira da Silva, Aníbal de Freitas, Basílio de Magalhães e, obviamente, Othoniel Mota, que ocupou a cadeira de Língua Portuguesa no recémcriado Ginásio de Ribeirão Preto.

\section{Othoniel de Campos Motta: vida e obra ${ }^{2}$}

Othoniel de Campos Motta ${ }^{3}$ nasceu em 16 de abril de 1878, em Porto Feliz, Estado de São Paulo. Filho de José Rodrigues Paes e Bernardina Deocleciana da Mota Paes, cursou em São Paulo os preparatórios para a Faculdade de Direito. Iniciou seus estudos de Teologia no Seminário Teológico Presbiteriano em 1897. Foi licenciado pelo Presbitério Oeste de São Paulo no dia 25 de julho de 1900, na Primeira Igreja de São Paulo, tendo sido moderador da cerimônia o rev. Lino da Costa. Neste período de licenciatura ao sagrado ministério, residiu em Santa Cruz do Rio Pardo, onde atendia às

\footnotetext{
${ }^{2}$ Parte do conteúdo aqui apresentado é um recorte da minha tese de doutorado sobre Othoniel Motta e sua gramatização, apresentada na PUC-SP em 2011: Lições de Portuguez e O meu idioma: a peregrinação histórico-gramatical de Othoniel Motta.

${ }^{3}$ Vale esclarecer que os documentos oficiais trazem a grafia Othoniel Motta e Otoniel Mota. No caso deste trabalho, preferimos o uso de Othoniel Motta, exceto em citações ou referências a nomes de logradouros públicos ou instituições. A maior parte dos dados biográficos de Motta foi extraída de $O$ Estandarte de 30 de abril de 1978. Outras referências importantes são: O Estado de São Paulo, de 29/04/1978; Diário da Manhã, de Ribeirão Preto, de 16/01/1957; Jornal do Comércio, do Rio de Janeiro, de 16/08/1951 e Folha da Manhã, de 18/08/1951.
} 
cidades de Piraju, Taquari, Fartura e Anhumas, esta no Paraná, onde mais tarde ergueuse a cidade de Ribeirão Claro.

No dia 14 de julho de 1901, foi ordenado ministro do evangelho, em Brotas, pelo mesmo Presbitério, tendo sido presidente da cerimônia o rev. Laudelino Oliveira Lima, e a parênese foi proferida pelo rev. Herculano de Gouvêa.

As questões políticas sempre estiveram no cenário da vida de O. Mota. No âmbito eclesiástico, por exemplo, O. Mota esteve no grupo que participou do grande cisma da Igreja Presbiteriana do Brasil, em 1903. Desde os tempos do Seminário, O. Mota tomou parte da discussão das questões maçônicas, que culminaram, finalmente, com a criação do Presbitério Independente, em 14 de julho de 1903, que deu origem à Igreja Presbiteriana Independente do Brasil - IPIB.

Em razão de seus trabalhos eclesiásticos, viajou o interior paulista, especialmente: Sorocaba, Tietê, Itapetininga, Bela Vista, Torre de Pedra, Bebedouro e Iacanga. Residiu por um tempo em Jaú. Nesta cidade, inclusive, ajudou na construção do templo da cidade. Daí transferiu-se para Ribeirão Preto. Nesta cidade, ajudou na Igreja Metodista, realizando conferências. Nesta ocasião refutou a conferencista Belen Sarraga. Foi professor de português no Ginásio de Ribeiro Preto, fundado em $1^{\circ}$ de abril de 1907. Este foi o primeiro ginásio do interior paulista e o terceiro do Estado, criado por decreto legislativo em 27 de dezembro de 1906. Hoje, o nome é Escola Estadual Prof. Otoniel Mota.

Motta viajou ainda para Guaxupé, pela região do Triângulo Mineiro, e foi copastor na Igreja de Grama. Depois foi para Campinas, onde assumiu o pastorado da Igreja nesta cidade, assumindo também aulas no Ginásio de Campinas. Finalmente, foi eleito pastor da Primeira Igreja de São Paulo, até que, em razão de questões doutrinárias, transferiu-se para a Igreja Cristã de São Paulo.

Exerceu, durante algum tempo, o cargo de Diretor da Biblioteca Pública de São Paulo - SP, e foi também professor de Filologia da Faculdade de Filosofia, Ciências e Letras da Universidade de São Paulo - USP. Fez parte da Sociedade de Estudos Filológicos de São Paulo e foi membro da Academia Paulista de Letras, na cadeira 17, cujo patrono foi Júlio Ribeiro e o fundador Silvio de Almeida. 
Casou-se com Rosalina de Barros Motta (filha de Antonio Paes de Barros e Maria Paes de Barros). ${ }^{4} \mathrm{O}$ casal teve os seguintes filhos e filhas: Maria Motta, Adelina Motta, José de Barros Motta, Emília Motta, Antônio de Barros Motta e Gerty Fink.

De sua grande influência no projeto linguístico da gramática brasileira, destacamse suas publicações teológicas nos órgãos da Imprensa Oficial Protestante do Brasil, como O Estandarte, A Semana Evangélica, O Cooperador Cristão, Cristianismo, revistas A Reforma, Cultura Religiosa, além de Lucerna e Unitas.

Além de suas publicações teológicas, Othoniel Motta publicou ainda várias outras obras, das quais se destacam: Ensaio linguístico - Lições de português (1918); O meu idioma (1918); Algum riso, muito siso (1918); Comentário aos Lusíadas; Comentários às Geórgicas, de Virgílio; Seleta moderna (s/d); Lirismo grego (1934); A Origem do lirismo português (1936); Horas filológicas (1937); Chave da língua - primeiras lições de gramática (1930); Do rancho ao palácio - Evolução da civilização paulista (1941); Através do Inventário (1944); O negro Tapanhuno (1944); Historietas (1946); Um pouco de folclore (1946); Cesário Mota - um estudo biográfico (1946); Livro de admissão, escrito em parceria (1950). O adorável bilhete ou a resposta à epístola a Filemon (s/d); O pronome "se" (1905); A evolução do gerúndio; Comentários ao livro de Atos dos Apóstolos; Evangelho de S. Mateus; Israel, sua terra e seu livro (1930); Questões Philologicas.

Motta ofereceu contribuição às Letras, ainda, encontrando tempo para realizar traduções para o idioma português, como os livros Valor (1946), Temas espirituais para pequenos e grandes, bem como $O$ amigo, todos de Charles Wagner.

De suas séries teológicas polêmicas, publicou, em 1933, os opúsculos: Lutero e o Pe. Leonel Franca, Lutero, a Bíblia e o Pe. Leonel Franca, A defesa do Pe. Leonel Franca, O papado e o Pe. Leonel Franca. E em 1938, publicou a série: Uma passagem interessante, Novas luzes, Paraíso e o Céu, A pregação além túmulo e Meu credo escatológico.

\footnotetext{
${ }^{4}$ No sítio eletrônico da Igreja Presbiteriana Independente do Brasil, lemos: 21/01/1940 - Organização do Departamento de Senhoras. Realizou-se o " $1{ }^{\circ}$ Congresso das Senhoras Presbiterianas Independentes", nesta data, sendo eleita a sua primeira presidente Rosalina Barros Motta, mas apenas em 1967 se criou oficialmente a Confederação de Senhoras da Igreja Presbiteriana Independente do Brasil, sendo sua $1^{a}$ presidente Dra. Maria Clemência Cintra Damião. http://www.ipib.org/index.asp?inc=articlessub\&articlescat=Fam\%EDlia\&articlesdbid=304 - Acesso em 25/06/2011.
} 
Motta recebeu diversas honras em razão de seus escritos serem revolucionários para o estudo gramatical da época. Numa correspondência, por exemplo, recebida de Wilhelm Meyer-Lübke ${ }^{5}$ e citada por Motta, lemos:

Monsieur, jê vous remercie de votre article Questões philologicas. La question que vous traitez est très difficile et pour cela très intéressante. Je suis disposé à accepter votre point de vue, contre l'opinion de Mr. Leite et de feu Moreira. - C'est um grand mérite de poursuivre ces études dans une région qui est aussi éloignée dês centres scientifiques que Le Brésil, et jê vous felicite de votre zele. J'espére bien que vouz continuerez. Bien à vous (Apud MOTTA, 1917:247). ${ }^{6}$

Sobre $O$ meu idioma, Osorio Duque Estrada afirmou: É dispensável encarecer o valor e a utilidade deste trabalho (Apud MOTTA, 1917:246). De Afrânio Peixoto, da Academia de Letras, Motta recebeu também elogios ao seu trabalho Lições de Português.

As suas Lições de Portuguez têm novidade didactica de alto valor, que deve permitir facilidade enorme ao ensino e à aprendizagem da língua: partir do concreto para o abstracto é regra natural de conhecimento e constitue o melhor merito das doutrinas pedagógicas de Pestalozzi.

Por isso, e creio que não me engano, o seu livro terá, e cada vez mais, um merecido bom exito (Apud MOTTA, 1917:247).

Motta recebeu, também, de dois outros grandes gramáticos, contemporâneos seus, referências importantes sobre suas obras. Eduardo Carlos Pereira e João Ribeiro se manifestaram sobre os trabalhos de Motta. Sobre a sua obra Ensaio Linguistico, Pereira admite a utilização da hipótese de Motta em sua Gramática Expositiva. Assim afirmou: A hypothese aventada pelo intelligente cathedratico Othoniel Motta, em seu interessante opúsculo Ensaio Linguistico, é altamente plausível, e, por assim consideral-a, partilheia na Grammatica Expositiva. E João Ribeiro, sobre a mesma obra Ensaio Linguistico, afirmou: Provera a Deus que todas as contribuições, estudos e tentativas feitas no assumpto fossem da alta valia da sua obrinha, tão bem pensada e escripta, em estylo tão agradável e tão claro. E ainda sobre um opúsculo teológico, intitulado Amor que santifica, Ribeiro elogiou: O livro é ao mesmo tempo encantador e instructivo em muitas

\footnotetext{
${ }^{5}$ Meyer-Lübke foi, de acordo com Cavaliere (2000:109), dentre os gramáticos indo-europeus, um dos que mais se detiveram sobre a etimologia das línguas românicas. Ele foi uma das referências teóricas nos estudos gramaticais brasileiros, especialmente no que se refere às questões filológicas.

${ }^{6}$ Senhor, agradeço-lhe a remessa de seu artigo Questões philologicas. O tema que o senhor desenvolve é muito difícil, por isso mesmo muito interessante. Estou disposto a acatar seu ponto de vista, contrário à opinião do senhor Leite e do falecido Moreira. - Há grande mérito na perquirição de tal estudo numa região tão afastada dos centros científicos como é o Brasil, razão por que lhe felicito o emprenho. Espero sinceramente que o senhor lhe dê seguimento. Saudações.
} 
das suas paginas, sem laivos de pedantismo e sempre ameno, agradavel e cheio de pensamentos nobilissimos (Apud MOTTA, 1917:248).

O. Mota faleceu no dia 14 de agosto de 1951. O enterro se deu no dia 15 de agosto, às 15 horas, com o féretro saindo da Capela Cristã, na rua Baronesa de Itu, 48, na capital paulista.

As referências póstumas em memória de O. Mota foram inúmeras. O Jornal do Comércio, do Rio de Janeiro, de 16 de agosto de 1951, registrou:

Em sua residência, na capital paulista, faleceu, às primeiras horas de ante-ontem, o Sr. Othoniel Motta, ilustre escritor e filólogo e figura de merecido realce nos meios culturais do país. Poucos estudiosos de nossa língua terão contribuído tanto quanto esse estudioso infatigável da ciência filológica e competente mestre brasileiro, a quem muitas gerações devem assinalados serviços ao lhe receberem preciosos ensinamentos, os colégios e academias em que Othoniel Motta prontificou como um valor inconteste.

O Jornal O Estado de São Paulo, na sexta-feira, 17 de agosto de 1951, publicou nota oficial da ata da Assembleia Legislativa Estadual, na qual se constava voto de pesar, proposto pelos deputados Gilberto Chaves e Camillo Ashcar, nos seguintes termos:

Requeremos se consigne em ata um voto de profundo pesar pelo falecimento do professor Otoniel Mota, filólogo, romancista, jornalista, ensaísta, sociólogo e orador, cuja vida construtiva e eminentemente cristã significou a expressão plena da harmonia existente entre a Ciência e a Fé.

Na Folha da Manhã, de 18 de agosto de 1951, publicou-se nota da Câmara dos Deputados nos seguintes termos:

Pela palavra do deputado Lauro Cruz, repercutiu no plenario da Camara o passamento do professor Otoniel Mota, falecido há dias nessa capital. Em comovida oração, o deputado udenista ressaltou as qualidades de homem de letras e ministro do evangelho, do extinto, funções que, como nenhum outro, soube honrar a dignificar. Alude ao vasto acervo literário que o extinto lega às gerações futuras, tanto no campo da filologia, como da religião, e fixa os seus esforços o campo da assistência social, fundando e dirigindo numerosas instituições filantropicas.

Na seccional de $O$ Estado de São Paulo em Campinas, de 18 de agosto de 1951, lemos: 
Teve à mais profunda repercussão nesta cidade, a noticia da morte do professor Otoniel Motta, que durante algum tempo foi catedratico de português do antigo Ginasio Estadual "Culto à Ciencia". A Congregação desse tradicional estabelecimento de ensino, reunida ontem, deliberou oficiar à família do extinto, apresentando-lhe os pesames dos corpos administrativo e docente da referida casa de ensino. Por proposta do prof. Francisco Ribeiro Sampaio, unanimemente aprovada, será dado o nome do Prof. Otoniel Mota, à sala dos professores a ser inaugurada ainda este ano. Ficou deliberado, de acordo com o sugerido pelo prof. Livio Tomas Pereira, que será procedida à inauguração do retrato do saudoso extinto, a sala da Congregação.

Na Folha da Manhã, de 23 de agosto de 1951, o professor Silveira Bueno ressaltou a importância da perda de Otoniel Mota para a língua nacional, especialmente no âmbito da filologia, destacando a fidelidade com que trabalhou no despertamento de uma cultura linguística brasileira, como também na Europa e nos demais países da América. Referindo-se à relevância de suas obras, Silveira Bueno afirmou: "Os dois Evangelhos de que foi grande ministro, o de Cristo e o de Camões, o eternizarão na face da terra assim como as suas obras já o eternizaram na presença de Deus".

No dia 29 de dezembro de 1951, realizou-se, às 20 horas e 30 minutos, cerimônia oficial na Biblioteca Municipal, com a presença dos membros da Sociedade de Estudos Filológicos de São Paulo, para homenagearem a memória de Motta.

As homenagens invadiram também o âmbito eclesiástico. De acordo com nota oficial “em memória do rev. prof. Otoniel Mota”, do Jornal A Gazeta, de São Paulo, de 31 de outubro de 1951, uma cerimônia religiosa seria realizada naquela noite, às 20 horas e 30 minutos, na Igreja Metodista Central, na rua Liberdade, 659, um culto em memória de Motta. Nesta cerimônia religiosa, foi presidente o Rev. Epaminondas Melo do Amaral, pastor da Igreja Cristã de São Paulo. Acerca do programa de culto, lemos:

Falará o prof. Albertino Pinheiro sobre a vida inspiradora do grande mestre desaparecido, que não só foi um grande cultor das letras como tambem um exemplar e piedoso cristão... Na ocasião serão cantados alguns hinos da lavra do rev. Otoniel Mota e o organista, dr. Darcy Prado, executará o programa musical.

Das homenagens pessoais eclesiásticas, destacamos a de Almeida Martins que, publicando em $O$ Estandarte, de 15 de setembro de 1951, referiu-se a Motta, como aquele que semeou com profusão as sementes benditas da instrução. E resume, então, o momento da perda de Motta para a Igreja e cultura brasileiras: 
Foi por essa razão que, ao ver o corpo do rev. Otoniel Mota baixar ao túmulo naquela tarde de 15 de agôsto, tive impressão, a qual, creio eu, foi a mesma de todos quantos lá se encontravam na tarde daquele dia: a de que naquele instante desaparecia com Otoniel Mota mais uma das glórias do evangelismo nacional.

Destaca-se, também, a referência póstuma do prof. Luís Gonzaga Pereira Campos que, comparando a morte de O. Mota à de Euclides da Cunha (20/01/1866 - 15/08/1909), no mesmo $O$ Estandarte, de 15 de setembro de 1951, registrou:

15 de agôsto!

Ao encerrar as justas homenagens a um dos maiores gênios da língua, Euclides da Cunha, chega-nos a triste notícia da morte de outro gigante das letras pátrias: Prof. Otoniel Mota.

Cobrem-se de luto as letras e o Evangelismo pátrios!

Cobrem-se de luto as inúmeras instituições idealizadas e protegidas por êle!

$\mathrm{Na}$ sua fecunda e benéfica trajetória, Otoniel Mota revelou-se sempre o paladino das causas justas e foi durante sua vida, a permanente esperança para todos os brasileiros, como lídimo defensor que era dos altos interêsses do Senhor e da nacionalidade.

\section{O meu idioma}

Dedicado à memória de Cesario Motta, $O$ meu idioma é uma das produções mais significativas de Motta. Apesar de o próprio autor declarar sua singela pretensão na obra, como se verá abaixo, o conteúdo reflete estudos filológicos e literários complexos e desafiadores para a sua época.

No Diário do Estado de São Paulo, de 4 de abril de 1928, na página 8991, lemos a indicação de $O$ Meu Idioma para os alunos do terceiro ano dos Ginásios do Estado, juntamente com a obra $O$ Exame de Portuguez, de Julio Nogueira.

A obra é dividida em três grandes partes. Na primeira, o autor privilegia os temas relativos à história da língua, à fonologia e à morfologia. Na segunda parte, o autor traz um compêndio de citações de textos latinos e portugueses, com a finalidade de se observar a progressão da história linguística dos textos. Na terceira parte, o autor insere seus próprios comentários aos textos latinos e portugueses da sessão anterior, sob a perspectiva da sintaxe histórica da língua. Finalmente, há um glossário dos "principaes termos archaicos", cuja nota de rodapé traz a informação de que "este glossário é feito de accordo com o de J. Nunes, appenso a Chrestomathia" (p.231), e um apêndice escrito por Adolpho Coelho apresentando a classificação genealógica das línguas. 


\section{Lições de Português}

Lições de Português é obra de grande relevância nas publicações de Motta, atestada pela encomenda em carta do diretor da Companhia Editora Nacional, O. Marcondes Ferreira, em sua 9a edição, encapando a "Biblioteca Pedagógica Brasileira: Livros Didáticos" - série aplicada ao ensino ginasial:

Ilmo. sr. Prof. Otoniel Mota

Capital

Prezado amigo

Seu livro LIÇÕES DE PORTUGUÊS vem sendo insistentemente procurado por professores e alunos de todo o País e essa procura tem sido tal que nos obriga a voltar à sua presença para insistir na sua publicação. Pensamos que o amigo não deve privar os estudantes brasileiros de tão precioso compendio.

Ficamos muito aguardando sua aquiescencia ao nosso pedido e sem mais, somos com estima e consideração,

de v.s.

Amos. Atos. Obrgs.

COMPANHIA EDITORA NACIONAL

O. Marcondes Ferreira

Diretor

Motta registrou este requerimento em seu prefácio às edições posteriores:

Este livro, em virtude de uma página de Castilho publicada há um século e transcrita por mim há cerca de trinta anos na $1^{a}$. edição da obra, foi julgado inconveniente para o ensino brasileiro.

Em virtude disso, esgotou-se a última edição.

A alunos, professores, diretores de ginásios que me interpelavam, dei sempre esta resposta: "Está esgotado e não será reimpresso".

Em virtude, porem, da carta retro, achei que não me assistia o direito de lesar o ensino de minha terra com a ausencia do volume no mercado e concordei em tirar nova edição, suprimindo a referida página.

Otoniel Mota

Seguindo o método de $O$ meu idioma, Lições de Português foi também dividido em três partes, e em dois livros. Na primeira parte, o autor se dedica aos fatos gramaticais, explicitando as questões próprias da sintaxe em 63 lições. Diferentemente dos demais 
livros, os quais traziam uma abordagem morfológica, este se apresenta mais discursivo. A primeira parte foi dedicada a alunos das $1^{\mathrm{a}}$ e $2^{\mathrm{a}}$ séries ginasiais. Na segunda parte, $\mathrm{o}$ autor reuniu, como seu costume, trechos de obras clássicas para serem analisadas pelos alunos do $3^{\circ}$ ano ginasial. Na terceira parte, que compõe o segundo livro juntamente com a parte anterior, o autor se dedica a comentar os trechos citados anteriormente, com a finalidade de expandir a análise dos fatos sintáticos defendidos na primeira parte.

\section{Chave da Língua}

A metodologia inovadora abraçada por Motta é clara. Ele afirma, no prefácio de Chave da Língua, que seu objetivo é superar os ideais de gramática clássicos e empreender uma gramática discursiva, aplicadas a "inteligencias incipientes" (p.9). Assim, ele afirma:

Era de esperar que eu chamasse a este pequeno trabalho Gramatica infantil. Não o fiz, porque quase voto horror a certas gramaticas infantis de que tenho conhecimento, mostrengos que principiam com as mais abstrusas noções, as quais poderão ser decoradas, mas jamais compreendidas pelas inteligencias incipientes.

Motta traz uma crítica direta ao estilo gramatical de Julio Ribeiro, ao afirmar:

Neste livrinho foi meu intuito evitar aos filhos dos outros o que não pude evitar aos meus, pois tive a desventura de ver uma filhinha entrar, por assim dizer, para um grupo escolar, sobraçando por ordem da professora a gramatica de Julio Ribeiro! Parece incrivel.

E para marcar sua escolha metodológica, registrou: Não dei ao livrinho o nome de gramatica, porque, a bem dizer, é êle uma reação contra as gramaticas: são antes palestras com os pequenos, e, quanto possivel, na lingua dos pequeninos. (Tarefa quasi sobrehumana!).

\section{Considerações Finais}

Othoniel Motta foi um sofisticado e profícuo gramático brasileiro na primeira metade do século 20. As obras para o ensino de Língua Portuguesa de Othoniel Motta se tornaram muito conhecidas e relevantes, juntamente com as de outros gramáticos protestantes, como Eduardo Carlos Pereira, tornando-se referenciais, inclusive em âmbito nacional. 
Othoniel Motta não foi somente divulgador de um modelo gramatical e educacional já estabelecido, como também participou de um contexto transitório que, por assim dizer, trouxe consigo conflitos e modificações próprias das gêneses teóricas. A defesa de um modelo didático-pedagógico e a instauração de um novo método - o analítico, em contraposição ao sintético -, representou um avanço nos estudos da língua brasileira, razão pelo qual seus textos tornaram-se básicos para a educação linguística.

Motta também se destacou muito no campo teológico, especialmente em razão de suas ideias polêmicas, próximas do liberalismo teológico, que o levaram ao rompimento com a Igreja Presbiteriana Independente do Brasil - IPIB, que há havia se separado, em 1903, da Igreja Presbiteriana do Brasil - IPB, instituição histórica e herdeira da Reforma Protestante do século 16 e, até os nossos dias, confessional e subscritora dos símbolos de fé oriundos de Westminster: a Confissão de Fé e os Catecismos Maior e Breve.

Os discursos gramaticais e religiosos de Motta trouxeram implicações para a sociedade em geral e, particularmente, nas áreas da Educação e da Igreja, mantenedoras da ordem e do imaginário social.

\section{REFERÊNCIAS}

ANTUNHA, H. C. G. A união e o Ensino Secundário na Primeira República. 271p. Dissertação (concurso de professor titular do Departamento de Metodologia de Ensino de Educação Comparada) - Faculdade de Educação da Universidade de São Paulo, Setor de Educação USP, São Paulo, 1980.

BAVINK, Herman. As maravilhas de Deus: instrução na religião cristã de acordo com a Confissão Reformada. São Paulo: Pilgrim Serviços e Aplicações; Rio de Janeiro: Thomas Nelson, 2021.

HILL, Christopher. O século das revoluções: 1603-1714. São Paulo: Unesp, 2012.

KUYPER, Abraham. Calvinismo. São Paulo: Cultura Cristã, 2002.

MOTTA, Othoniel. O Meu Idioma. 2 ed. São Paulo e Rio de Janeiro: Weiszflog Irmãos, 1917.

MOTTA, Othoniel. Chave da Língua. 3 ed. São Paulo: Cia Editora Nacional, 1933.

MOTTA, Othoniel. O Paraíso e o Céu. São Paulo: Revista dos Tribunais, 1938.

MOTTA, Othoniel. Lições de Português. 9 ed. São Paulo: Companhia Editora Nacional, 1941.

PACKER, James I. Entre os gigantes de Deus: uma visão puritana da vida cristã. São José dos Campos: Fiel, 1996.

PLANTINGA, Alvin. Crença Cristã Avalizada. São Paulo: Vida Nova, 2018. 
RYKEN, Leland. Santos no mundo: os puritanos como realmente eram. São José dos Campos: Fiel, 1992.

XAVIER, W. L. V. Lições de Portuguez e O meu idioma: a peregrinação histórico-gramatical de Othoniel Motta. 2011. Tese (Doutorado) - PUC/SP, 2011. 